Published as: Oliveira F., Leterrier Y., Månson J.-A.E., Sereda O., Neels A., Dommann A., Damjanovic D., Process Influences on the Structure, Piezoelectric and Gas-Barrier Properties of PVDF-TrFE Copolymer, J. Polym. Sci. B: Polym. Phys., 52, 496-506 (2014). DOI 10.1002/polb.23443. (C) 2014. This manuscript version is made available under the CC-BY-NC-ND 4.0 license http://creativecommons.org/licenses/by-nc-nd/4.0/

\title{
Process influences on the structure, piezoelectric and gas-barrier properties of PVDF-TrFE (81-19 mol\%) copolymer
}

Fabiane Oliveira ${ }^{1}$, Yves Leterrier ${ }^{1 *}$, Jan-Anders Månson ${ }^{1}$, Olha Sereda $^{2}$, Antonia Neels ${ }^{2}$, Alex Dommann², Dragan Damjanovic ${ }^{3}$

(1) Laboratoire de Technologie des Composites et Polymères (LTC)

École Polytechnique Fédérale de Lausanne (EPFL)

CH-1015 Lausanne, Switzerland

(2) Centre Suisse d'Electronique et de Microtechnique (CSEM)

Jaquet Droz 1

CH-2002 Neuchâtel, Switzerland

(3) Laboratoire de Céramique (LC)

École Polytechnique Fédérale de Lausanne (EPFL)

CH-1015 Lausanne, Switzerland

$\left(^{*}\right)$ corresponding author: yves.leterrier@epfl.ch 


\section{GRAPHICAL ABSTRACT}

Process influences on the structure, piezoelectric and gas-barrier properties of PVDF-TrFE (81-19 mol\%) copolymer

Fabiane Oliveira, Yves Leterrier, Jan-Anders Månson, Olha Sereda, Antonia Neels, Alex Dommann, Dragan Damjanovic

A 10-fold decrease of $\mathrm{O}_{2}$ permeability of polyvinylidene fluoride trifluoroethylene copolymer films occurs upon annealing between the Curie temperature and the melting point of the polymer. Annealing moreover increases the piezoelectric coefficient of the films. These changes are controlled by a crystalline phase transition, from the paraelectric $\alpha$-phase to the ferroelectric $\beta$-phase. These combined gas barrier and piezoelectric properties are key to increase the sensitivity of piezoelectric gas-barrier liners for high-pressure storage vessels.

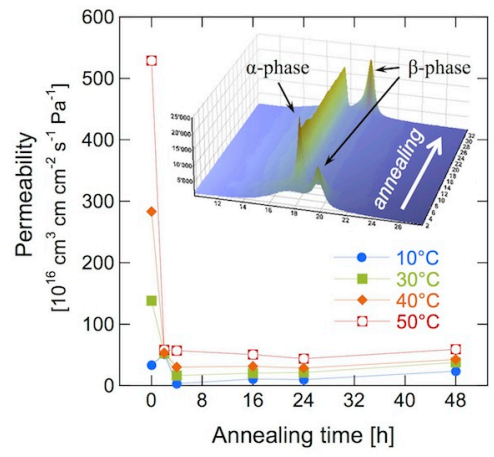




\begin{abstract}
The influence of annealing between the Curie transition and the melting point of solvent cast polyvinylidene fluoride trifluoroethylene copolymer films on the crystalline structure, mechanical and electrical properties and oxygen permeability is investigated. Annealing leads to remarkable changes in the structure and properties of the copolymer, within the first four hours of treatment, and with kinetics depending on the temperature. The crystallinity increases by $19 \%$ (relative), resulting in a $10 \mathrm{~K}$ increase in the Curie transition, a $4 \mathrm{~K}$ increase of the melting temperature and a $2 \mathrm{~K}$ decrease in the glass transition temperature. $\mathrm{A}$ crystalline phase transition from the paraelectric $\alpha$-phase to the ferroelectric $\beta$-phase is also evidenced using in-situ X-ray diffraction. The elastic modulus is found to increase by more than three-fold at room temperature and the loss peak at the glass transition is considerably reduced. The piezoelectric coefficient is found to increase by $40 \%$ and the dielectric properties are significantly changed. The most remarkable influence is the ten-fold reduction of the oxygen permeability, with a drastic reduction of the activation energy for oxygen transport. The improvement in oxygen barrier properties of the annealed copolymer is attributed to the restricted mobility of oxygen molecules in the semicrystalline polymer with nanometer sized crystallites.
\end{abstract}

Key-words: PVDF-TrFE, annealing, crystallinity, piezoelectric properties, oxygen permeability. 


\section{INTRODUCTION}

The piezoelectric properties and related crystalline conformations of polyvinylidene fluoride (PVDF) based materials are well-documented in the literature. ${ }^{1}$ Among the different PVDF polymorphisms $(\alpha, \beta, \gamma, \delta$, and $\varepsilon)$ the polar all-trans, ferroelectric $\beta$-phase (orthorhombic conformation) is responsible for the greatest piezo activity in these materials. ${ }^{2}$ The conversion to and/or enhancement of the $\beta$-phase have been investigated by different approaches that include uniaxial or biaxial stretching, ${ }^{3-6}$ poling processes,${ }^{7}$ annealing or combined processing techniques $^{8-11}$ as detailed in a recent review article. ${ }^{12}$

The introduction of trifluoroethylene ( $\mathrm{TrFE}$ ) co-monomer into VDF leads the copolymer to crystallize directly into the $\beta$-phase without requiring mechanical processing before poling usually applied to PVDF. ${ }^{13-15}$ The proportion of TrFE determines the crystalline structures whilst the VDF content controls the stability of the electric structure. ${ }^{16}$ At molar concentrations of TrFE above 11\%, the defects introduced by the presence of bulky fluorine prevent the formation of the trans-gauche, paraelectric $\alpha$-phase (hexagonal conformation) below the Curie temperature. ${ }^{17,}{ }^{18}$ Besides chemical composition, post thermal-electrical processing also influence the crystalline morphology of PVDF-TrFE and consequently its piezoelectric properties. ${ }^{13,14,19-25}$ Specifically, annealing at temperatures above the Curie transition causes relaxation and reorientation of the polymer chains, and induces changes in crystallite sizes and inner structure of the crystal lattice ${ }^{26}$ as well as the increase of the crystallinity of the polymer. ${ }^{27-29}$ Piezoelectric coefficients $d_{33}$ as high as $-38 \mathrm{pC} / \mathrm{N}$ have been reported for single crystal films of PVDF-TrFE (75-25 mol\%) after stretching and annealing in the paraelectric $\alpha$-phase. ${ }^{30}$ 
A further benefit of increased crystallinity is the reduction of the polymer gas permeability. Crystals are considered to be impermeable to most molecules even if imperfect ${ }^{31}$ and they moreover increase the tortuosity of the transport path. The permeability of semi-crystalline polymers to small molecules has been studied for a vast range of materials including fluoropolymers. The latter case was motivated by the development of fuel cells and examples include studies of permeability of several gases in PVDF, ${ }^{32} \mathrm{CO}_{2}$ in PDVF-graphite composites, ${ }^{33} \mathrm{H}_{2}$ and $\mathrm{He}$ in PVDF and sulfonated PVDF, ${ }^{34} \mathrm{O}_{2}$ in PVDF-based protonexchange membranes, ${ }^{35}$ and $\mathrm{H}_{2}, \mathrm{O}_{2}$ and $\mathrm{N}_{2}$ in perfluoroalkoxy-polytetrafluoroethylene copolymers. $^{36}$

In none of these studies, however, the piezoelectric properties and the gas barrier properties of the polymers were analyzed simultaneously. Such combined properties would be useful for applications such as self-sensing liners for gas storage vessels, where the liner would provide a low permeability to gases while serving as a pressure sensor integrated into the vessel. The objective of the present work was thus to investigate the influence of annealing on the piezoelectric and oxygen permeation properties of PVDF-TrFE and correlate the experimental results to the thermally induced changes in the crystalline structure of the polymer.

\section{EXPERIMENTAL SECTION}

\section{Materials and processing}

PVDF-TrFE copolymer with $81 \mathrm{~mol} \%$ of VDF used in this study was supplied by Solvay in powder form. Solvent cast films were prepared by dissolution of PVDF-TrFE in methyl ethyl ketone (Acros Organics, $>99 \%$ ) at $60^{\circ} \mathrm{C}$ during $2 \mathrm{~h}$. The solution was poured into $14 \mathrm{~cm}$ 
diameter petri dishes and placed at $70^{\circ} \mathrm{C}$ overnight in low vacuum to let the solvent evaporate. The total solvent evaporation was gravimetrically confirmed. Transparent films with thicknesses around 19-22 $\mu \mathrm{m}$ were divided into $30 \times 30 \mathrm{~mm}^{2}$ samples, which were subsequently annealed at $120^{\circ} \mathrm{C}, 130^{\circ} \mathrm{C}$ and $140^{\circ} \mathrm{C}$ for $2,4,8,16,24$ and $48 \mathrm{~h}$ prior to testing.

\section{Characterization methods}

X-ray diffraction experiments were carried out in transmission mode on a STOE Transmission X-ray Powder Diffraction System (STADIP) using $\mathrm{CuK}_{\alpha 1}$ radiation (Ge(111) monochromator) and a linear Position Sensitive Detector (PSD). The data were collected using film samples placed between two acetate foils in the $2 \theta$ range of 4 to $90^{\circ}$ (step size 0.1 , 30 s per step). The average crystallite size $L$ in the samples was estimated using the Scherrer equation:

$$
B_{\text {size }}(2 \theta)=\frac{K \lambda}{\cos (\theta) L}
$$

where $K$ is a shape factor taken equal to $0.9, \lambda$ is the wavelength and $B_{\text {size }}(2 \theta)$ is the line broadening at full width at half maximum (FWHM). For the as-cast samples the FWHM could not be measured due to the overlap of the $\alpha$-phase and $\beta$-phase peaks. For the annealed samples the 200 and 110 reflections of the $\beta$-phase were used. The contribution of the FWHM from the instrument was also taken into account, using $\mathrm{Si}$. The relative fraction of $\beta$ crystalline phase $F(\beta)$ was estimated from XRD patterns.

In-situ high temperature XRD studies of the solvent cast PVDF-TrFE films were also performed in order to investigate the dynamics of the transition from the paraelectric $\alpha$-phase 
to the ferroelectric $\beta$-phase. A PANalytical X'Pert PRO MPD diffractometer equipped with a high temperature chamber (HTK 16MSW) was used. Measurements were carried out with a $\mathrm{CuK}_{\alpha}$ radiation under a $\theta / 2 \theta$ configuration in a range from $10^{\circ}$ to $30^{\circ}$ in $2 \theta$ (corresponds to the region of the strongest reflections). The sample was heated on a Ta strip up to $130^{\circ} \mathrm{C}$ under vacuum. XRD patterns were acquired at selected temperatures during the heating, isothermal and cooling steps.

Differential scanning calorimetry (DSC) tests were performed on a TA Instrument DSC Q100 under nitrogen environment. The instrument temperature and heat flow were calibrated monthly using an indium reference. Samples with a weight between 6 and $10 \mathrm{mg}$ placed in an aluminum pan were cooled to $-50^{\circ} \mathrm{C}$ at $10 \mathrm{~K} \mathrm{~min}^{-1}$ and held at this temperature for $3 \mathrm{~min}$ before heating to $160^{\circ} \mathrm{C}$ at the same rate.

Dynamic mechanical analysis (DMA) was performed on a TA Instrument DMA Q800, under tensile mode. The applied strain amplitude was set to 0.001 , the preload force was $0.1 \mathrm{~N}$ and the frequency was $1 \mathrm{~Hz}$. Rectangular samples of gage length $12.5 \mathrm{~mm}$ and width $5 \mathrm{~mm}$ were cooled to $-50^{\circ} \mathrm{C}$ at $10 \mathrm{~K} \mathrm{~min}^{-1}$ and held at this temperature for $3 \mathrm{~min}$ before heating to $155^{\circ} \mathrm{C}$ at $3 \mathrm{~K} \mathrm{~min}^{-1}$.

Thermogravimetric analysis (TGA) was performed on a Mettler Toledo TGA/SDTA 851, using alumina crucibles of $150 \mu \mathrm{L}$. Each sample weighed around $10 \mathrm{mg}$ and was heated from

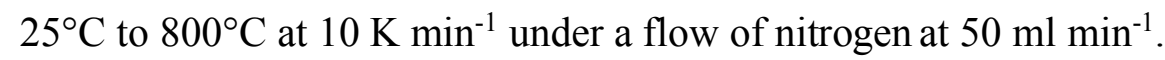

The direct piezoelectric coefficient, $d_{33}$, (i.e., charge or strain coefficient in the thickness direction) was measured on $1 \mathrm{~cm}$ diameter circular samples, using a homemade Berlincourt- 
type $d_{33}$ meter. The sample thickness was measured prior to testing with an accuracy of $1 \mu \mathrm{m}$. One layer of chromium followed by a gold layer were deposited on each side of the films by sputtering using an EMS 575X machine (Electron Microscopy Sciences, Hatfield, PA, USA). The coated film samples were poled at $110^{\circ} \mathrm{C}$ for 30 min under an electric field of $750 \mathrm{kV} \mathrm{cm}^{-1}$ and cooled to room temperature for another $30 \mathrm{~min}$ under the same field. The choice of the optimum polarization field to maximize $d_{33}$ without increasing the current leakage of PVDF-TrFE films was obtained by applying a series of electric fields during various poling tests. In fact the increase in $d_{33}$ is controlled by the reorientation of the $\beta$-phase dipoles, which is highly dependent of the polarization process. Special care was exercised to achieve uniform electrode sputtering, temperature and electric field. It was observed that fields higher than $750 \mathrm{kV} \mathrm{cm}^{-1}$ led to a breakdown of the samples. After being poled, the piezoelectric coefficient of each film was measured every 30 min during 2 to $3 \mathrm{~h}$, to detect ageing effects.

The oxygen permeance (or oxygen transmission rate, OTR) of the polymer was measured on samples cut from the solvent cast films using an Oxygen Permeation Analyser-Systech Instrument Model 8001 with sensitivity equal to $0.008 \mathrm{~cm}^{3} / \mathrm{m}^{2} /$ day $/$ bar. The area of the samples was $5 \mathrm{~cm}^{2}$ and the activation energy for oxygen transport was derived from OTR tests carried out at $10,20,30,40$ and $50^{\circ} \mathrm{C}$, under $0 \%$ of relative humidity and 1 bar of oxygen pressure. Two samples were measured simultaneously using the two chambers of the instrument. The oxygen permeability, $P$, was calculated using:

$$
P=t \cdot O T R
$$

where $t$ represents the thickness of the sample. 


\section{MICROSTRUCTURAL ANALYSIS}

\section{Analysis of crystalline phases}

DSC thermograms measured during the heating runs of PVDF-TrFE films annealed at different temperatures and times are reproduced in Figure 1. Additional annealing during the DSC experiment itself was considered to be negligible since the time spend in the $120^{\circ} \mathrm{C}$ $150^{\circ} \mathrm{C}$ range was only $3 \mathrm{~min}$ (heating rate of $10 \mathrm{~K} \mathrm{~min}^{-1}$ ). Two endothermic peaks were detected for all investigated films. The first event, around $120^{\circ} \mathrm{C}$ corresponds to the ferroelectric to paraelectric transition (Curie temperature, $\left.T_{C}\right)^{14,37}$ partially overlapped with an exothermic peak. This exothermic event corresponds to a crystallization process typical of solvent cast PVDF-TrFE, ${ }^{27}$ controlled by the solvent evaporation rate and resulting biphase crystalline structure. ${ }^{10}$ The second event near $150^{\circ} \mathrm{C}$ is related to the melting of the crystalline phase $\left(T_{m}\right)$.

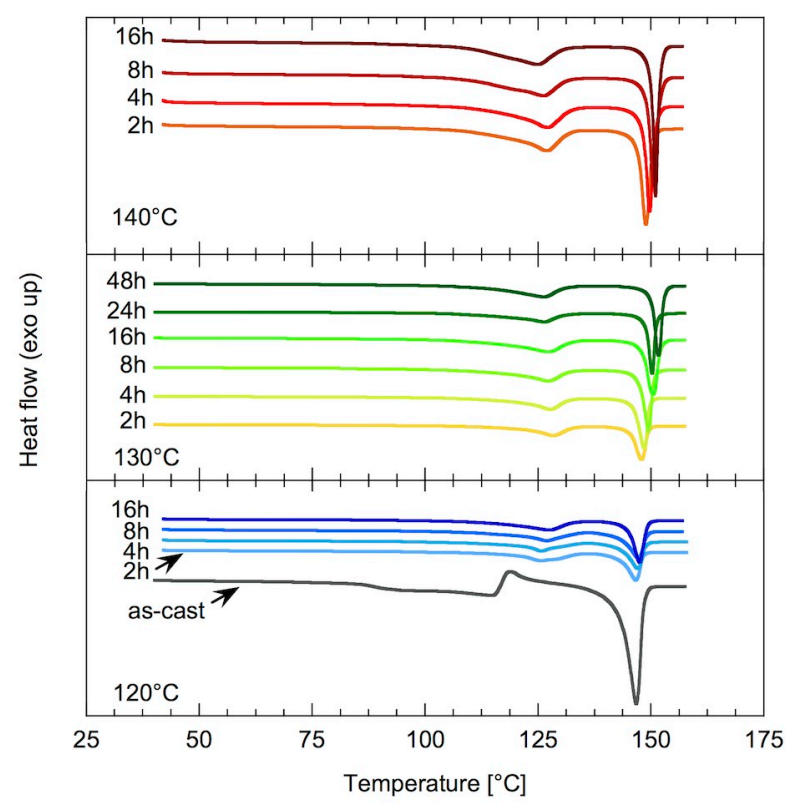

Figure 1. DSC thermograms of PVDF-TrFE films as-cast and annealed at $120^{\circ} \mathrm{C}, 130^{\circ} \mathrm{C}$ and $140^{\circ} \mathrm{C}$ for different times as indicated. 
A significant change of the ferroelectric to paraelectric transition occurred upon annealing, with the disappearance of the exothermic peak and the development of a broad transition peak in the temperature range of $120-130^{\circ} \mathrm{C}$ for all investigated conditions. In contrast, the melting temperature of the copolymer did not change significantly upon annealing.

Figure 2 shows X-ray diffractograms at room temperature of the PVDF-TrFE copolymer films before and after annealing at different times and temperatures. For the as-cast film a sharp diffraction peak of the (200) and (110) planes at $2 \theta \approx 19.9^{\circ}$ attributed to the $\beta$-phase and a shoulder peak at $2 \theta=17.1^{\circ}-18.4^{\circ}$ relative to the non-polar $\alpha$-phase were evident. ${ }^{13}$ Two others peaks at $2 \theta=35^{\circ}$ and $2 \theta \approx 41^{\circ}$ attributed to the (001) and (201) diffraction plans of the $\beta$ polymorph were present, and which were consistent with previously reported results for PVDF-TrFE with other molar compositions. ${ }^{13,22,38}$ When the samples were annealed at $T_{C}<T<T_{m}$ the rapid (less than $2 \mathrm{~h}$ ) decay of the $\alpha$-peak and development of the polar $\beta$ phase was evident. The dynamics of this crystalline phase transition is further detailed in the Section 3.2. 


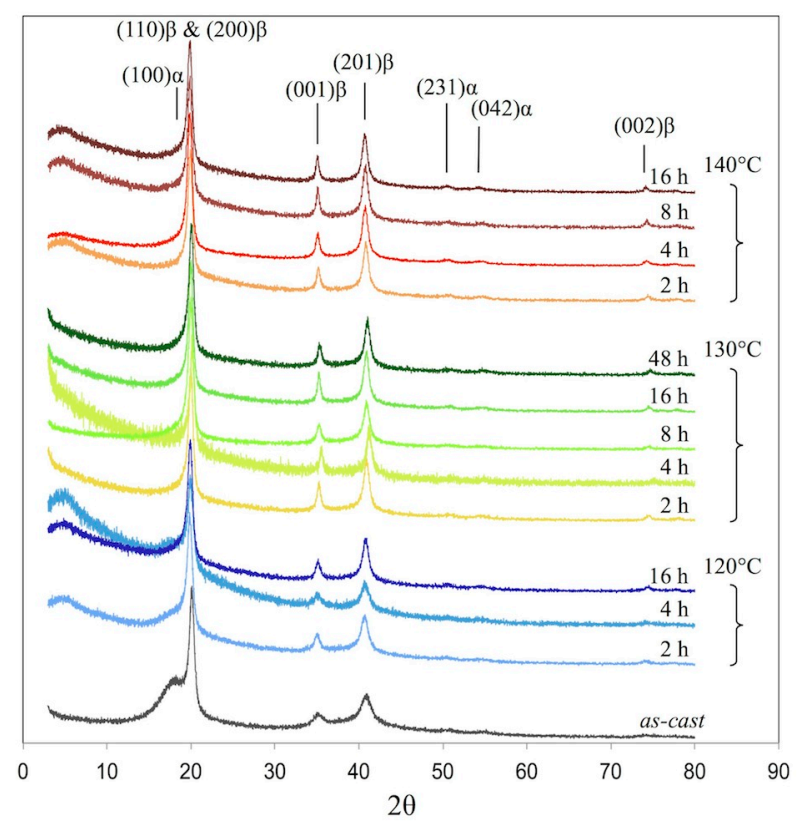

Figure 2. X-ray diffraction patterns (transmission mode) of PVDF-TrFE films as-cast and annealed at $120^{\circ} \mathrm{C}, 130^{\circ} \mathrm{C}$ and $140^{\circ} \mathrm{C}$ for different times as indicated.

Figures 3 and 4 regroup the salient calorimetry and XRD data as a function of annealing time. The glass transition temperature determined using dynamic mechanical analysis (Section 3.3) is also shown in Figure 3. The $T_{C}$ behavior was found to be comparable for all investigated annealing temperatures, with a rapid increase from $119^{\circ} \mathrm{C}$ to approximately $127^{\circ} \mathrm{C}$ after $2 \mathrm{~h}$, and no further large changes for longer times. A careful look reveals a slight influence of the annealing temperature after the initial $2 \mathrm{~h}$ increase. Annealing at $120^{\circ} \mathrm{C}$ for $16 \mathrm{~h}$ further increased $T_{C}$ to $128^{\circ} \mathrm{C}$. In contrast, $T_{C}$ decreased to $126^{\circ} \mathrm{C}$ after annealing at $130^{\circ} \mathrm{C}$ for $16 \mathrm{~h}$, and to $125^{\circ} \mathrm{C}$ after annealing at $140^{\circ} \mathrm{C}$ for $16 \mathrm{~h}$. A similar behavior has been reported by Barique and Ohigashi, ${ }^{22}$ and was explained in terms of changes in the Gibbs free energies in the orthorhombic $\beta$-phase and hexagonal $\alpha$-phase during annealing. 


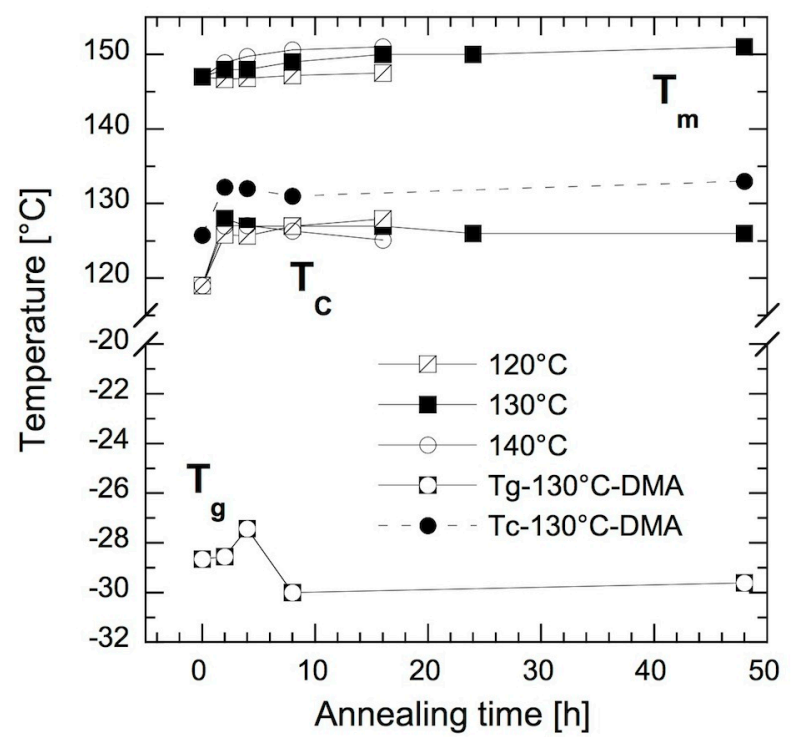

Figure 3. Melting temperature $\left(T_{m}\right)$, Curie transition temperature $\left(T_{C}\right)$ and glass transition temperature $\left(T_{g}\right)$ of solvent cast PVDF-TrFE films as a function of annealing time at $120^{\circ} \mathrm{C}$, $130^{\circ} \mathrm{C}$ and $140^{\circ} \mathrm{C}$.

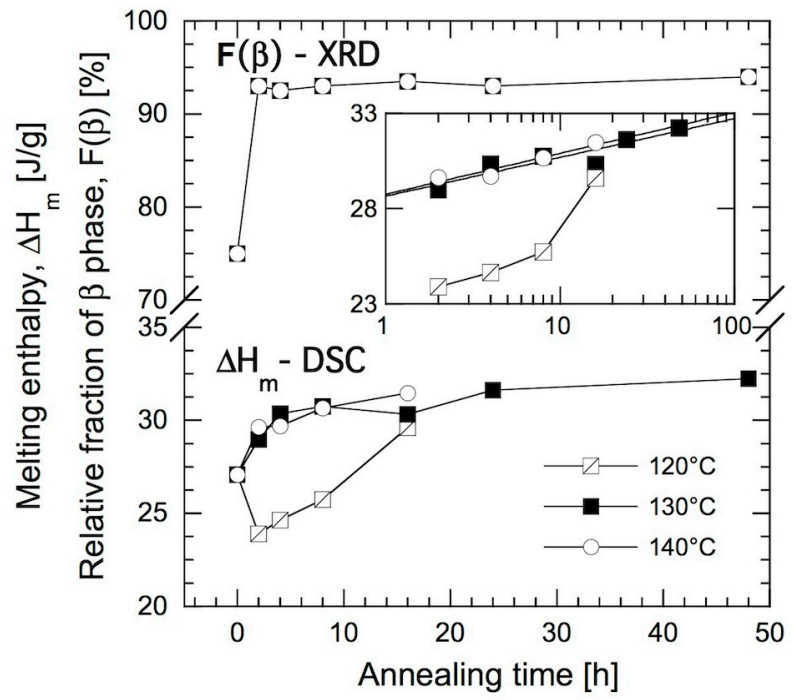

Figure 4. Melting enthalpy $\left(\Delta H_{m}\right)$ of solvent cast PVDF-TrFE films as a function of annealing time at $120^{\circ} \mathrm{C}, 130^{\circ} \mathrm{C}$ and $140^{\circ} \mathrm{C}$ and relative fraction of crystalline $\beta$-phase, $F(\beta)$, as a function of annealing time at $130^{\circ} \mathrm{C}$. The inset shows $\Delta H_{m} v$ s. annealing time in logarithmic scale. 
The melting point, $T_{m}$, of the as-cast film was $147^{\circ} \mathrm{C}$. It remained unchanged upon annealing at $120^{\circ} \mathrm{C}$, i.e. at a temperature close to the original $T_{C}$ of the as-cast film, whereas the melting enthalpy (hence, the crystallinity) first dropped by $12 \%$ (from $27.1 \mathrm{~J} / \mathrm{g}$ to $23.9 \mathrm{~J} / \mathrm{g}$ ), and then increased to $29.6 \mathrm{~J} / \mathrm{g}$ after $16 \mathrm{~h}$ (when $T_{C}$ had become higher than $120^{\circ} \mathrm{C}$ ). Annealing below $T_{C}$ favors the removal of gauche defects introduced into chain molecules of the ferroelectric phase although this effect is restricted by the low mobility of molecular chains in this temperature region. ${ }^{22,28}$ Upon annealing at $130^{\circ} \mathrm{C}$ and $140^{\circ} \mathrm{C}$ (i.e. in the hexagonal phase), $T_{m}$ shifted slightly toward higher temperatures, reaching $151^{\circ} \mathrm{C}$ after $48 \mathrm{~h}$ annealing at $130^{\circ} \mathrm{C}$, or after $16 \mathrm{~h}$ annealing at $140^{\circ} \mathrm{C}$. The melting enthalpy of the films annealed at these two temperatures above the $T_{C}$ increased logarithmically with annealing time, up to $32.2 \mathrm{~J} / \mathrm{g}$ (a $19 \%$ increase from the as-cast film). The corresponding increase of crystallinity was attributed to the increase in crystallite size along the molecular chain direction and to changes in the inner structure of the crystal lattice. ${ }^{26}$ The relative fraction of polar $\beta$-phase in the ascast film was $75 \%$. It increased to $93 \%$ after $2 \mathrm{~h}$ and to $94 \%$ after $48 \mathrm{~h}$ of annealing at $130^{\circ} \mathrm{C}$ (the relative fraction of $\alpha$-phase thus decreased from $25 \%$ to $6 \%$ ). Almost all trans-gauche conformation sequences from $\alpha$-phase were replaced by all-trans sequences from $\beta$-phase. ${ }^{39}$ These large structural changes (simultaneous increase of crystallinity and of the proportion of orthorhombic phase) reveal the considerable decrease in the number of gauche defects in the orthorhombic phase, which took place upon annealing.

\section{In-situ high temperature XRD analysis}

In order to clarify the dynamics of the transformation of the hexagonal $\alpha$-phase into the orthorhombic $\beta$-phase, which occurred upon annealing at $T_{C}<T<T_{m}$, two different in-situ XRD experiments were performed, using two temperature profiles. In the first experiment, the 
sample was heated from room temperature to $75^{\circ} \mathrm{C}$ in one step, and then stepwise from $75^{\circ} \mathrm{C}$ to $125^{\circ} \mathrm{C}$ with $10 \mathrm{~K}$ steps. After each step, the temperature was maintained for $5 \mathrm{~min}$ followed by the XRD measurement. The sample was subsequently heated to $130^{\circ} \mathrm{C}$ and diffraction patterns were collected for $2 \mathrm{~h}$, followed by rapid cooling back to room temperature. In the second experiment the diffractograms were recorded during both heating and cooling at following temperatures: $25^{\circ} \mathrm{C}, 80^{\circ} \mathrm{C}, 100^{\circ} \mathrm{C}, 115^{\circ} \mathrm{C}, 120^{\circ} \mathrm{C}, 125^{\circ} \mathrm{C}$ and $130^{\circ} \mathrm{C}$ (maintained for $5 \mathrm{~min}$ at each step). Figure 5 shows the diffractograms in $2 \mathrm{D}\left(10^{\circ}<2 \theta<30^{\circ}\right)$ and in the form of 3D-isolines. The diffraction pattern at room temperature shows the presence of the two phases, a clear peak at $19.9^{\circ}$ (in $2 \theta$ ) of $\beta$-phase and a shoulder at $17.8^{\circ}$ (in $2 \theta$ ) of $\alpha$-phase. Phase coexistence and thermal hysteresis were evident as the sample was gradually heated and then cooled down through the phase transition. In the first experiment, a shoulder rose upon heating and became a well-resolved second peak at a temperature of about $100^{\circ} \mathrm{C}$. The paraelectric phase peak continued to grow at the expense of the ferroelectric $\beta$-phase peak until the latter disappeared at a temperature of $115^{\circ} \mathrm{C}$, leaving only the paraelectric phase peak. Rapid cooling to room temperature (rate of approximately $35 \mathrm{~K} \mathrm{~min}^{-1}$ ) reversed this phase conversion process, and at room temperature the paraelectric $\alpha$-phase was almost entirely transformed into the ferroelectric $\beta$-phase. In the second experiment, a similar behavior was observed during the heating step. Upon slow cooling from $130^{\circ} \mathrm{C}$ (average rate of approximately $3 \mathrm{~K} \mathrm{~min}^{-1}$ ), only the paraelectric phase peak was evident down to $80^{\circ} \mathrm{C}$. Upon further cooling to $25^{\circ} \mathrm{C}$, the paraelectric $\alpha$-phase transformed into the ferroelectric $\beta$ phase. This phase transformation follows the behavior of a first-order phase transition, ${ }^{40}$ which is highly dependent on the rate of heating and cooling. In the present case, the phase change upon cooling proceeded very rapidly even if the film was cooled very slowly, owing to large difference in the free energy between the hexagonal phase and orthorhombic phase at $T_{C}{ }^{22}$ This is a key result to further optimize the process cycles and achieve a very high 
proportion of $\beta$-phase. The proportion of $\beta$-phase thus exhibited a hysteretic behavior upon thermal cycling as sketched in Figure 5. This behavior was evidenced for other PVDF-TrFE compositions, ${ }^{41}$ and is reflected by hysteresis of viscoelastic properties ${ }^{42}$ and microhardness. ${ }^{43}$
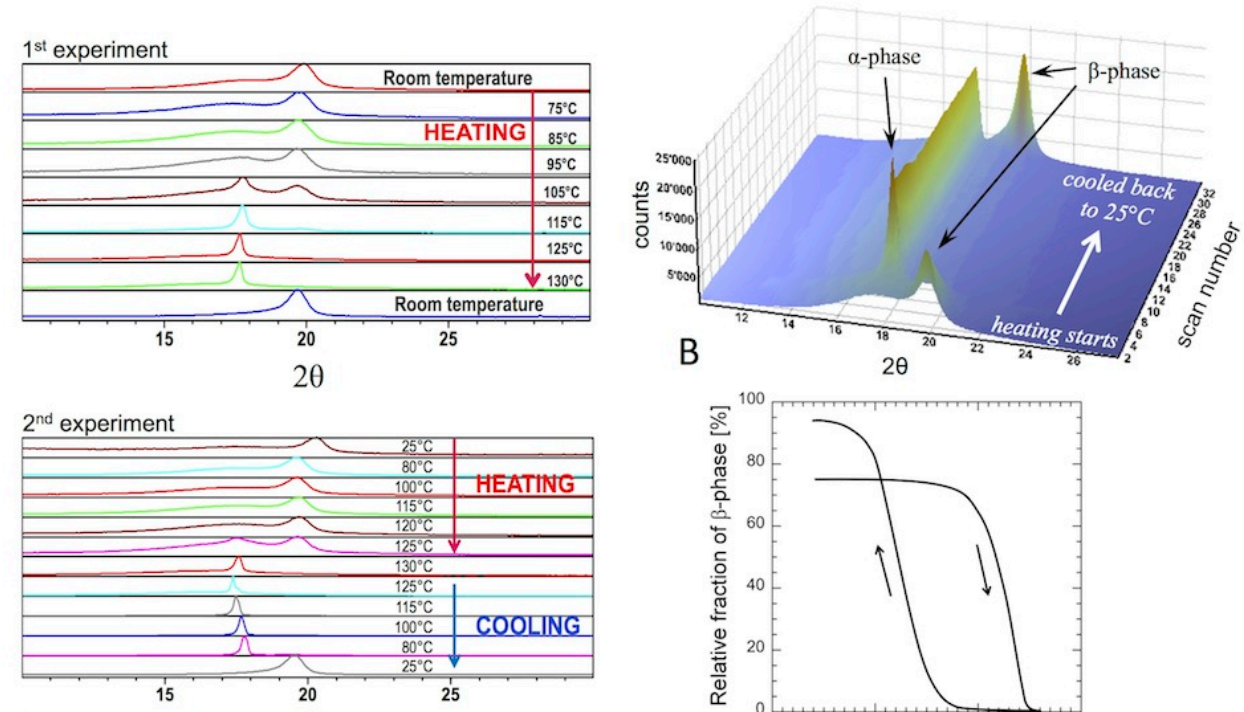

A

$2 \theta$

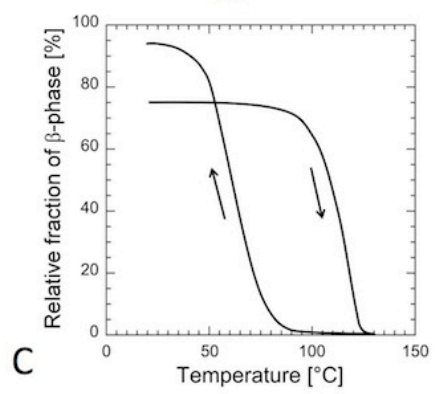

Figure 5. (A) 2D views of the diffractogram during heating and cooling of the solvent cast PVDF-TrFE film ( $1^{\text {st }}$ experiment: cooling at $35 \mathrm{~K} \mathrm{~min}^{-1}$ on top, and $2^{\text {nd }}$ experiment: cooling at $3 \mathrm{~K} \mathrm{~min}^{-1}$ on bottom), (B) 3D isolines-view of the X-ray patterns obtained during heating and cooling of the solvent cast PVDF-TrFE film, (C) sketch of the hysteresis in the thermallyinduced transformation of hexagonal $\alpha$-phase into orthorhombic $\beta$-phase.

\section{Dynamic mechanical analysis}

The influence of annealing at $130^{\circ} \mathrm{C}$ on the temperature dependence of the storage modulus $\left(E^{\prime}\right)$ and the ratio of loss modulus to storage modulus $(\tan \delta)$ of the copolymer is shown in Figure 6. At temperatures below $-40^{\circ} \mathrm{C}$ the storage modulus of both solvent cast and annealed films was similar. Around $-40^{\circ} \mathrm{C}$ the modulus of as-cast PVDF-TrFE film dropped abruptly corresponding to the glass transition. The associated peak in $\tan \delta$ at $-29^{\circ} \mathrm{C}$ is a characteristic 
of the segmental motions of the amorphous regions ( $\beta$-relaxation ${ }^{7,44}$ or $T_{g l}$ transitionrelaxation $^{45}$ ). With increasing temperature, $E$ ' continued decreasing smoothly while three relaxation processes were observed in the form of broad peaks around $21^{\circ} \mathrm{C}, 57^{\circ} \mathrm{C}$ and $98^{\circ} \mathrm{C}$. Similar events were also detected in another for another PVDF-TrFE copolymer (7723 mol\%). ${ }^{46}$ These processes include molecular mobility within the crystalline ferroelectric structure $\left(\alpha\right.$-relaxation $\left.{ }^{7}\right)$ and other relaxation processes associated with the motions of crystalline defects and lamellar surfaces. ${ }^{44}$ At $120^{\circ} \mathrm{C}$ the modulus started to increase and a peak in $\tan \delta$ appeared at $126^{\circ} \mathrm{C}$. This effect resulted from the complex phase transformations identified in the in-situ XRD experiments, which also took place during the DMA experiments since the heating rate was rather low $\left(3 \mathrm{~K} \mathrm{~min}^{-1}\right)$. The modulus eventually decreased again before the melting point, when the experiment was stopped.

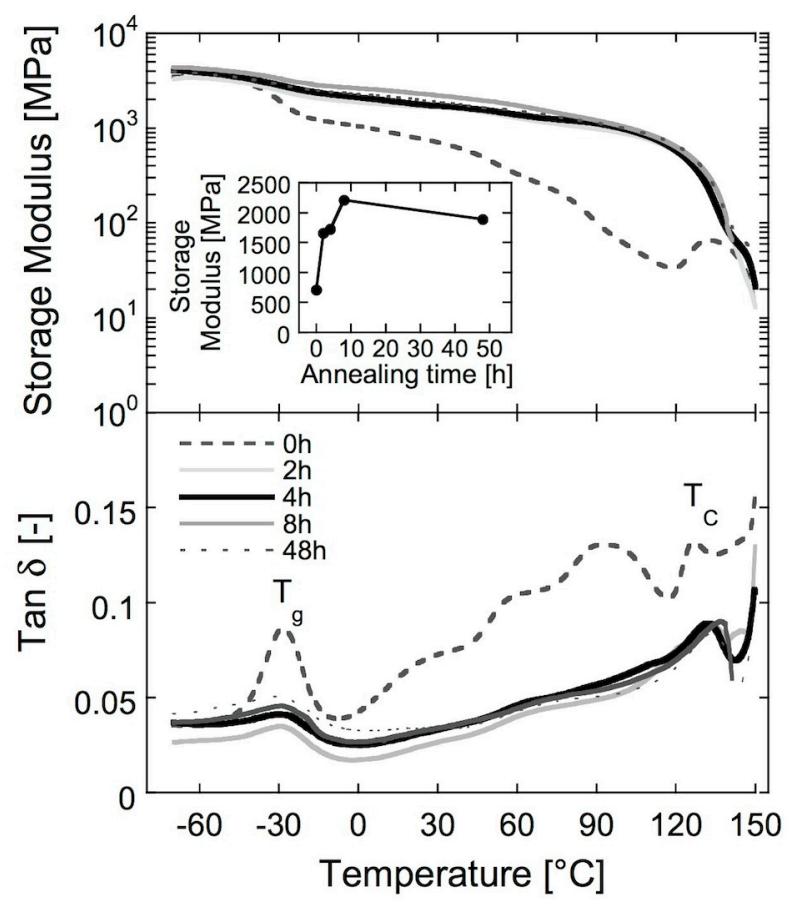

Figure 6. Storage modulus and tan $\delta$ of solvent cast PVDF-TrFE films annealed at $130^{\circ} \mathrm{C}$ and at different times as indicated. The inset shows the storage modulus at $30^{\circ} \mathrm{C}$ for different annealing times. 
It is evident that annealing had a considerable impact on the modulus of the copolymer, with a large reduction of the drop at the glass transition, a much less pronounced decrease with temperature, and almost no detectable effect around the Curie transition. The $\beta$-relaxation was much less pronounced, a result of the increase in crystallinity, ${ }^{45}$ and the additional relaxations above $0^{\circ} \mathrm{C}$ could hardly be detected. In contrast the tan $\delta$ peak at the Curie transition was as strong as for the as-cast copolymer. As shown in the inset in the figure, annealing during few hours at $130^{\circ} \mathrm{C}$ was enough to increase the storage modulus at $30^{\circ} \mathrm{C}$ more than three-fold. At higher temperatures up to $120^{\circ} \mathrm{C}$ (data not shown in the inset) the increase was by more than an order of magnitude. Such a huge increase, and the quasi disappearance of the secondary relaxation processes reflect the formation of more perfect crystalline structures upon annealing, rather than the $19 \%$ increase in crystallinity shown in Figure 3 (see e.g. the review of Grubb). ${ }^{47}$

The $T_{g}$ and $T_{C}$ extracted from the tan $\delta$ curves of Figure 6 are reported in Figure 2. The $T_{g}$ increased by $2 \mathrm{~K}$ up to $4 \mathrm{~h}$ of annealing, and then dropped by $1 \mathrm{~K}$ for longer annealing times. The moderate increase in $T_{g}$ for short annealing times was also observed by Dalle Vacche et al. ${ }^{46}$ The changes of $T_{C}$ upon annealing mimicked the calorimetry data, with a difference of approximately $5 \mathrm{~K}$ between the two types of measurements. Such a difference could be expected since the molecular scales relevant for viscoelasticity and heat capacity are also different, ${ }^{48}$ besides using different heating rates. ${ }^{49}$

\section{ELECTRICAL PROPERTIES}

\section{Piezoelectric coefficient}

The influence of annealing at $130^{\circ} \mathrm{C}$ on the piezoelectric response of PVDF-TrFE films is 
depicted in Figure 7. The piezoelectric coefficient $d_{33}$ of the as-cast copolymer was equal to $13 \mathrm{pC} / \mathrm{N}$, and increased to $18 \mathrm{pC} / \mathrm{N}$ after $4 \mathrm{~h}$ of annealing, after which time it leveled off to a value of $17 \pm 1 \mathrm{pC} / \mathrm{N}$. The increase of $d_{33}$ values of annealed films correlated with the increase in the proportion of $\beta$-phase. Interestingly, no significant aging was detected when $d_{33}$ was measured as a function of time (see inset in the figure), as was found in a previous work. ${ }^{50}$

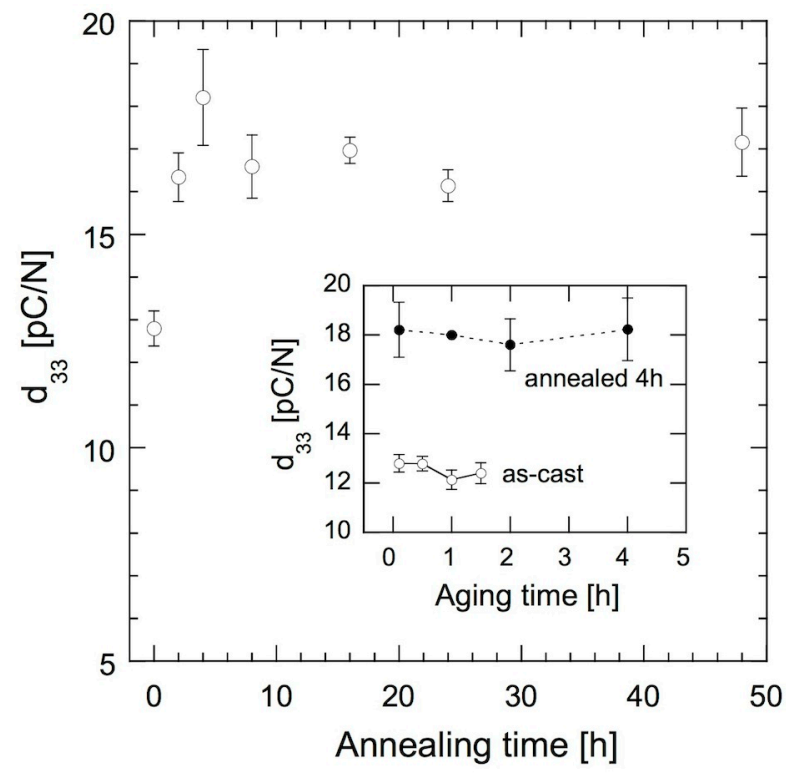

Figure 7. Piezoelectric coefficient $d_{33}$ of solvent cast PVDF-TrFE films as a function of annealing time at $130^{\circ} \mathrm{C}$. The inset shows the coefficient $d_{33}$ of the copolymer, as-cast (open symbols) and annealed $4 \mathrm{~h}$ at $130^{\circ} \mathrm{C}$ (black symbols), during aging at room temperature.

\section{Relative permittivity}

The relative permittivity and losses as function of frequency of PVDF-TrFE films, before and after different annealing steps and before and after poling are shown in Figure 8. The decrease of permittivity and increase of loss as frequency increased toward $1 \mathrm{MHz}$ indicated a relaxation process usually attributed to the $\alpha$-relaxation process and associated with the glass transition. ${ }^{51}$ The anomaly in loss of poled samples at $\sim 100 \mathrm{kHz}$ (also visible in permittivity for 
samples annealed at $2 \mathrm{~h}$ and $4 \mathrm{~h}$ ) was due to a piezoelectric resonance. We did not see an increase in loss at low frequencies that is attributed to ionic conductivity, ${ }^{51}$ suggesting that our samples had a low concentration of impurities. The permittivity decreased after poling for all samples. The largest decrease was observed for the samples annealed for $4 \mathrm{~h}$. Several processes could have contributed to this decrease, including lower density of ferroelectric domain walls in poled samples (i.e., better orientation of dipoles along poling field direction), removal of residual $\alpha$-phase and general decrease of disorder in the system. ${ }^{51,52}$

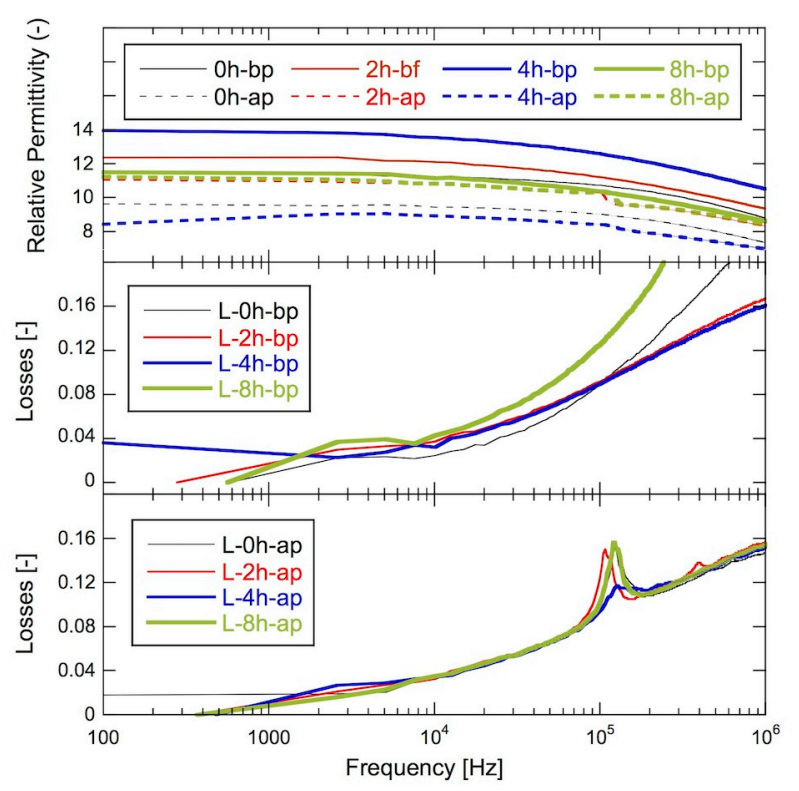

Figure 8. Relative permittivity and losses as function of frequency of PVDF-TrFE films, ascast and annealed at $130^{\circ} \mathrm{C}$ for different times as indicated, before poling (bp) and after poling (ap).

Figure 9 displays the influence of annealing at $130^{\circ} \mathrm{C}$ on the relative permittivity at $1 \mathrm{MHz}$ of unpoled PVDF-TrFE during heating through the Curie transition. The increase of $T_{C}$ upon annealing was in agreement with the calorimetry data shown in Figure 3 . The difference in $T_{C}$ between the first and second heating run for the non-annealed sample was probably due to annealing effects during the measurement. Note that the anomaly at $60^{\circ} \mathrm{C}$ observed during the 
first heating run was not observed during the second heating run made on as-cast films. The $T_{C}$ decreased slightly during the second heating run made on the film annealed for $4 \mathrm{~h}$. The likely reason for the decrease is that during the first heating the sample was heated to $150^{\circ} \mathrm{C}$, close to the melting temperature, which may have removed some of the effects of the $4 \mathrm{~h}$ annealing.

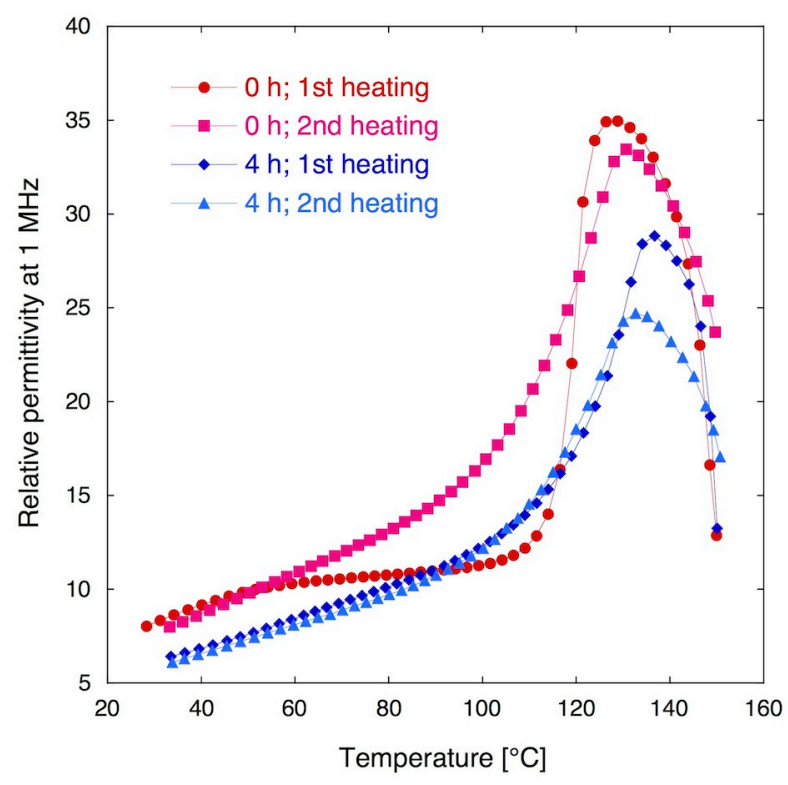

Figure 9. Relative permittivity at $1 \mathrm{MHz}$ of unpoled PVDF-TrFE, as-cast and annealed $4 \mathrm{~h}$ at $130^{\circ} \mathrm{C}$, during a first and a second heating scans through the Curie transition.

\section{OXYGEN PERMEATION}

The influence of annealing at $130^{\circ} \mathrm{C}$ on the oxygen permeability $(P)$ of PVDF-TrFE films at different temperatures is shown in Figure 10. The OTR of the as-cast, $20 \mu \mathrm{m}$ thick film at $20^{\circ} \mathrm{C}$ was equal to $162 \mathrm{~cm}^{3} \mathrm{~m}^{-2} \mathrm{day}^{-1} \mathrm{bar}^{-1}$. The corresponding permeability was equal to $66.2 \pm 8.810^{-16} \mathrm{~cm}^{3}(\mathrm{STP}) \mathrm{cm} \mathrm{cm}^{-2} \mathrm{~s}^{-1} \mathrm{~Pa}^{-1}$ (these units will be omitted in the rest of the text for convenience), and it increased almost ten-fold upon heating to $50^{\circ} \mathrm{C}$. This value is very close to that reported for PVDF (63). ${ }^{32}$ 


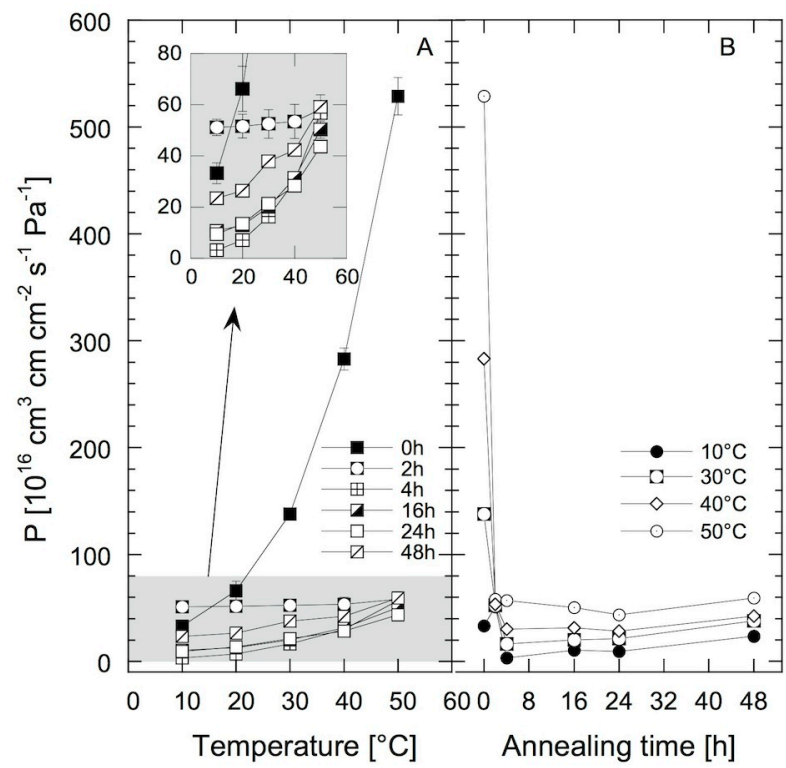

Figure 10. Influence of annealing at $130^{\circ} \mathrm{C}$ on the oxygen permeability $(P)$ of solvent cast PVDF-TrFE films as a function of (A) temperature and (B) annealing time.

Annealing above $T_{C}$ markedly decreased the $\mathrm{O}_{2}$ permeability of PVDF-TrFE films and reduced its temperature dependence. For instance, annealing for $4 \mathrm{~h}$ decreased the permeability of the polymer more than ten-fold, down to 3.2 at $10^{\circ} \mathrm{C}$ and 7.1 at $20^{\circ} \mathrm{C}$ (i.e., the OTR of the $20 \mu \mathrm{m}$ thick film was equal to 15 and $33 \mathrm{~cm}^{3} \mathrm{~m}^{-2}$ day $^{-1} \mathrm{bar}^{-1}$ at $10^{\circ} \mathrm{C}$ and $20^{\circ} \mathrm{C}$, respectively). These permeation values are comparable with those of other polar semicrystalline polymers. ${ }^{53}$ The relation between the permeation behavior and the change of crystallinity is discussed in the following section.

Figure 11 shows the permeation data in Arrhenius coordinates. The linearity between $\operatorname{Ln}(P)$ and the inverse of the absolute temperature confirmed that the transport of oxygen in the copolymer was a thermally activated rate process. The activation energy was found to be equal to $58.2 \pm 0.9 \mathrm{~kJ} / \mathrm{mol}$ for the as-cast polymer, a value which is rather high compared to other polymers, with activation energies for oxygen transport usually in the range of $10 \mathrm{~kJ} / \mathrm{mol}$ (silicone rubber) to $56 \mathrm{~kJ} / \mathrm{mol}$ (polyvinyl chloride). ${ }^{54}$ 


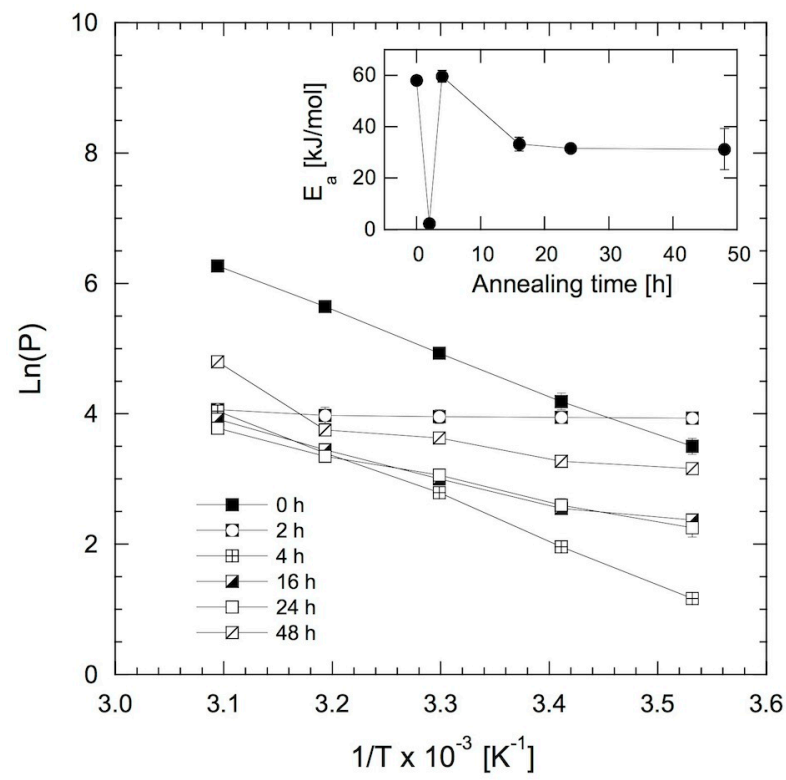

Figure 11. Oxygen permeability $(P)$ of solvent cast PVDF-TrFE films annealed at $130^{\circ} \mathrm{C}$ for different times as indicated as a function of the temperature in Arrhenius coordinates. The inset shows the activation energy $E_{a}$ as function of the annealing time.

In addition to the considerable decrease in permeation, a considerable change of the activation energy (i.e., the fundamental transport mechanism) became evident upon annealing. After $2 \mathrm{~h}$, the activation energy dropped to an extremely low value of $2.4 \pm 0.7 \mathrm{~kJ} / \mathrm{mol}$. Permeation tests were repeated on a new series of solvent cast and annealed films and the same result was obtained. The reason behind this exceptional and anomalous property is discussed in the following section. After $4 \mathrm{~h}$, the activation energy increased to $59.7 \pm 2.3 \mathrm{~kJ} / \mathrm{mol}$, i.e., back to the value as for the as-cast film. Again, this result was reproducible. Then, at longer annealing times, the activation energy decreased by a factor of two and stabilized to a value of approximately $32 \mathrm{~kJ} / \mathrm{mol}$. The latter activation energy is equal to that for $12 \mu \mathrm{m}$ thick semicrystalline polyethylene terephthalate films. ${ }^{55}$ 


\section{DISCUSSION}

The influence of annealing of the crystalline structure and electric properties of the solvent cast PVDF-TrFE copolymer described in previous sections confirmed the main findings of a number of previous studies. The transition from the paraelectric $\alpha$-phase to the ferroelectric $\beta$-phase was characterized by a large temperature hysteresis and removal of a large part of crystalline defects, resulting in a relative proportion of polar $\beta$-phase of $94 \%$ and a piezoelectric coefficient equal to $18 \mathrm{pC} / \mathrm{N}$. The analysis of the oxygen barrier properties of the copolymer uncovered in the present work adds to the knowledge on such materials, although the huge changes in the activation energy for oxygen transport remain puzzling.

Figure 12 shows the oxygen permeability of the copolymer as a function of the volume fraction of crystallites, $X_{v}$, calculated from the melting enthalpy data (Figure 3) as:

$$
X_{v}=X_{m} \cdot \frac{\rho}{\rho_{c}}=\frac{\Delta H_{m}}{\Delta H_{m}^{0}} \cdot \frac{\rho}{F(\beta) \rho_{\beta}+(1-F(\beta)) \rho_{\alpha}}
$$

where $X_{m}$ is the crystallinity of the polymer (i.e., weight fraction) determined from the ratio of the measured melting enthalpy $\Delta H_{m}$ (Figure 3) and the melting enthalpy of a PVDF-TrFE crystal $\Delta H_{m}^{0}$. The latter was estimated as $100.6 \mathrm{~J} / \mathrm{g}$ from a linear interpolation of the values for PVDF $(104.5 \mathrm{~J} / \mathrm{g})^{56}$ and a 68-32 PVDF-TrFE copolymer $(99.2 \mathrm{~J} / \mathrm{g})^{57} . \mathrm{F}(\beta)$ is the relative proportion of $\beta$-phase, $\rho$ is the density of the copolymer $\left(1.78 \mathrm{~g} / \mathrm{cm}^{3}\right), \rho_{c}$ is the density of the crystalline phase, calculated from the proportion $\mathrm{F}(\beta)$ (Figure 3 ) and the density of the $\alpha$ phase crystals $\left(1.99 \mathrm{~g} / \mathrm{cm}^{3}\right)$ and $\beta$-phase crystals $\left(1.90 \mathrm{~g} / \mathrm{cm}^{3}\right) .{ }^{58}$ 


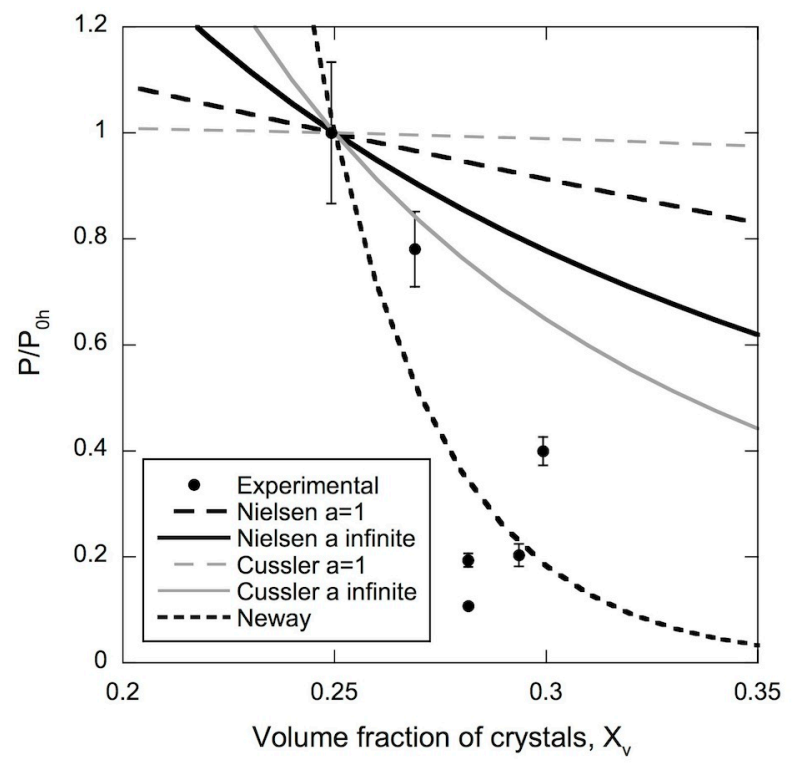

Figure 12. Oxygen permeability P of PVDF-TrFE (normalized with respect to the permeability of the as-cast polymer, $\left.P_{0 h}\right)$ vs. volume fraction of crystals (Eq. 3). Dots: experimental data; lines: theoretical data for various models as indicated ( $a$ is the aspect ratio of the crystals).

A number of factors may be invoked to explain the behavior shown in Figure 10, the first being crystallinity of the polymer. Crystallites are impermeable and thus reduce the overall solubility of the gas molecules in the polymer. Crystallites also act as obstacles and decrease the diffusivity of the molecules. Additional effects related to the immobilization of polymer chains from the amorphous phase at the surface of the crystallites may take place. These combined effects of reduced solubility and diffusivity lead to a non-linear dependence of permeability on $X_{v}{ }^{59,60}$ Several two-phase models of such dependence have been developed to following the initial model of Michaels and Bixler: ${ }^{61}$

$$
P=S D=\frac{S_{a} D_{a}\left(1-X_{v}\right)^{2}}{\xi f}
$$


where $D$ is the diffusivity, $S$ is the solubility, subscript $a$ stands for the amorphous phase, $f$ is a chain immobilization factor and $\xi$ is the tortuosity. The factor $f$ reflects the constraining effect of the crystallites on the amorphous chain segments. The tortuosity was related to the crystalline fraction through a geometric impedance factor $\tau=D / D_{a}=\xi /\left(1-X_{v}\right)$, which Michaels and Bixler related to the aspect ratio of the crystals. Similarly, the permeation of small molecules in polymer nanocomposites with clay particles has been described by several authors with explicit formulations of the geometric impedance factor (e.g. refs [ $\left.{ }^{62-65}\right]$, as reviewed by Takahashi et al. ${ }^{66}$ ). The classic Nielsen ${ }^{62}$ (Eq. 5) and $\operatorname{Cussler}^{63}$ (Eq. 6) 'nanocomposite' models have been used to analyze the permeation properties of polyethylene terephthalate ${ }^{31}$ and $\mathrm{PVDF},{ }^{58}$ respectively:

$$
\begin{gathered}
\frac{P}{P_{0}}=\frac{1-X_{v}}{1+a X_{v} / 2} \\
\frac{P}{P_{0}}=\frac{1-X_{v}}{1+\left(a X_{v} / 2\right)^{2}}
\end{gathered}
$$

where $a$ is the aspect ratio of the crystallites. These two models are shown in Figure 12, for the two extreme cases of aspect ratio $a=1$ and $a=$ infinite. It is evident that both models largely underestimate the measured drop of permeability with increasing crystallinity. An alternative empirical approach was devised by Gedde and coworkers in the form of an exponential dependence for the diffusivity, ${ }^{67}$ rewritten in terms of relative permeability as:

$$
\frac{P}{P_{0}}=\left(1-X_{v}\right) \exp \left\{b\left(1-X_{v}\right)\right\}
$$

where $b$ is an adjustable factor. This model also shown in the figure provides a reasonable fit to the experimental data (using $b=32.57$ ). 
An alternative phenomenon to the tortuous path should thus be invoked. The kinetic diameter of $\mathrm{O}_{2}$ is equal to $0.347 \mathrm{~nm} .{ }^{68}$ This value turns out to be comparable with the average distance $d$ between nearest-neighbor crystallites in the PVDF-TrFE owing to the nanometer dimensions of the crystallites. This distance $d$ can be calculated as a function of the crystallite radius $r$ using the model developed by Tewari et al. ${ }^{69}$ and assuming that crystallites are monodisperse spheres organized in the polymer into a three-dimensional uniform random spatial arrangement:

$$
d=\left\langle H_{1}\right\rangle-2 r=r\left(K_{1}\left(\frac{3 \phi}{4 \pi}\right)^{-1 / 3}\left[1+B_{1}\left(\frac{\phi}{\phi_{c p}}\right)^{2 / 3}\right]-2\right)
$$

where $\left\langle H_{1}\right\rangle$ is the distance between the cores of first nearest neighbor particles, $K_{1}=0.554$, $B_{1}=1.062$, and $\phi_{c p}=\pi / \sqrt{ } 18$ is the highest volume fraction for close-packed spheres. Eq. (7) shows that the average distance between neighbor crystallites very quickly drops with increasing fraction. For $7 \mathrm{~nm}$ radius crystallites (average size determined by XRD), the distance is equal to $3.23 \mathrm{~nm}$ for a volume fraction of $10 \%$, decreases to $0.77 \mathrm{~nm}$ for a volume fraction of $30 \%$, and becomes equal to the diameter of the oxygen molecule for a critical volume fraction of $47 \%$. For $3.1 \mathrm{~nm}$ radius crystallites the critical fraction is equal to $30 \%$ (i.e., the fraction of crystals in the annealed samples). This simplified approach shows that, due to the nanometer dimensions of the crystallites, small changes in crystallite size and volume fraction may have a considerable influence on the transport of oxygen molecules within the polymer. It may also explain the apparent anomalous activation energy finding shown in Figure 11 due to a particular combination of size and fraction. In the present case, annealing for few hours at $130^{\circ} \mathrm{C}$ increased the fraction of crystallites with no detectable change in size. A fraction of these crystallites became close enough to block the transport of oxygen molecules. 
The combination of piezo-electric properties and gas barrier performance is particularly relevant to develop novel self-sensing liner membranes for high-pressure gas storage vessels with reduced gas losses and improved safety both in dynamic mode (ultrafast response time in case of emergency such as impact) and in static mode (signal integration for storage and health monitoring). Adequate designs (such as protective coatings on the electrode facing the gas and dedicated electrical equipment) would be required to avoid electrical problems and ensure protection against explosion in conformance to IEC/EN 60079-0 ff, due to charge accumulation on the piezoelectric liner surface under increasing pressure. A remaining challenge for such self-sensing high-pressure storage vessels would be to account for the possible change of piezo-electric behavior of the polymer due to sorption of gas molecules.

\section{CONCLUSIONS}

PVDF-TrFE copolymer films were prepared by solvent casting and subjected to annealing treatments at temperatures $T_{C}<T<T_{m}$ for periods of time up to $48 \mathrm{~h}$. The analysis of the crystalline structure, mechanical, electrical and oxygen barrier properties led to the following conclusions.

Annealing at $120^{\circ} \mathrm{C}$ (close to $T_{C}$ ) led to a $10 \mathrm{~K}$ increase of $T_{C}$ within the first two hours owing to the removal of conformational defects, but did not change the $T_{m}$. The crystallinity initially decreased (a 10\% relative drop) and then slowly increased (relative increase of $10 \%$ after $16 \mathrm{~h}$ of annealing). A significantly different behavior was observed upon annealing in the hexagonal phase, with similar rapid increase of $T_{C}$ at $130^{\circ} \mathrm{C}$ and $140^{\circ} \mathrm{C}(10 \mathrm{~K}$ after $2 \mathrm{~h})$, a logarithmic increase in crystallinity (relative increase of $19 \%$ after $48 \mathrm{~h}$ at $130^{\circ} \mathrm{C}$ ), a 
progressive increase of $T_{m}\left(4 \mathrm{~K}\right.$ after $48 \mathrm{~h}$ at $130^{\circ} \mathrm{C}$, or after $16 \mathrm{~h}$ at $\left.140^{\circ} \mathrm{C}\right)$, and a $2 \mathrm{~K}$ decrease in the glass transition temperature. A crystalline phase transition from the paraelectric $\alpha$-phase to the ferroelectric $\beta$-phase was evidenced during the cooling stage following annealing above $T_{C}$, leading to a proportion of $\beta$-phase of $94 \%$. This phase change proceeded very rapidly owing to large difference in the free energy between the hexagonal phase and orthorhombic phase at $T_{C}$. The elastic modulus was found to increase by more than three-fold and the loss peak at the glass transition was considerably reduced. The piezoelectric coefficient was found to increase by $40 \%$ and the dielectric properties were significantly changed.

The most remarkable influence of annealing in the hexagonal phase was the ten-fold reduction of the oxygen permeability, with a drastic reduction of the activation energy for oxygen transport. The improvement in oxygen barrier properties of the annealed copolymer could not be explained using classic nanocomposite permeation models, and was attributed to the restricted mobility of oxygen molecules within the very tight, sub-nanometer spaces between the crystallites.

\section{ACKNOWLEDGEMENTS}

The authors acknowledge the Nano-Tera initiative of the Swiss National Science Foundation for funding the work.

\section{REFERENCES}

1. H. S. Nalwa, Ferroelectric Polymers: Chemistry: Physics, and Applications. Marcel Dekker Inc., New York, 1995. 
2. $\quad$ H. S. Nalwa, J. Macromol. Sci. C: Polym. Rev. 1991, C31, 341-432.

3. S. Lanceros-Mendez, J. F. Mano, A. M. Costa, V. H. Schmidt, J. Macromol. Sci. B: Phys. 2001, B40, 517-527.

4. A. Salimi, A. A. Yousefi, J. Polym. Sci. B: Polym. Phys. 2004, 42, 3487-3495.

5. M. V. Mhalgi, D. V. Khakhar, A. Misra, Polym. Eng. Sci. 2007, 47, 1992-2004.

6. H. Guo, Y. Zhang, F. Xue, Z. Cai, Y. Shang, J. Li, Y. Chen, Z. Wu, S. Jiang, Cryst. Eng. Comm. 2013, 15, 1597-1606.

7. V. Sencadas, S. Lanceros-Mendez, J. F. Mano, Thermochim. Acta 2004, 424, 201-207.

8. $\quad$ R. Gregorio, J. Appl. Polym. Sci. 2006, 100, 3272-3279.

9. M. C. Branciforti, V. Sencadas, S. Lanceros-Mendez, R. Gregorio, J. Polym. Sci. B: Polym. Phys. 2007, 45, 2793-2801.

10. R. Gregorio, D. S. Borges, Polymer 2008, 49, 4009-4016.

11. D. L. Chinaglia, R. Gregorio, J. C. Stefanello, R. A. Pisani Altafim, W. Wirges, F. Wang, R. Gerhard, J. Appl. Polym. Sci. 2010, 116, 785-791.

12. P. Martins, A. C. Lopes, S. Lanceros-Mendez, Prog. Polym. Sci. 2013, in press (http://dx.doi.org/10.1016/j.progpolymsci.2013.07.006).

13. A. J. Lovinger, T. Furukawa, G. T. Davis, M. G. Broadhurst, Polymer 1983, 24, 12251232.

14. A. J. Lovinger, T. Furukawa, G. T. Davis, M. G. Broadhurst, Polymer 1983, 24, 12331239 .

15. K. Tashiro, K. Takano, M. Kobayashi, Y. Chatani, H. Tadokoro, Polymer 1984, 25, 195-208.

16. K. El-Hami, A. Ribbe, S. Isoda, K. Matsushige, Chem. Eng. Sci. 2003, 58, 397-400.

17. J. Datta, A. K. Nandi, Polymer 1994, 35, 4804-4812.

18. J. Datta, A. K. Nandi, Polymer 1997, 38, 2719-2724.

19. K. Koga, H. Ohigashi, J. Appl. Phys. 1986, 59, 2142-2150.

20. J. Hirschinger, B. Meurer, G. Weill, Polymer 1987, 28, 721-726.

21. M. C. Christie, J. I. Scheinbeim, B. A. Newman, J. Polym. Sci. B: Polym. Phys. 1997, 35, 2671-2679.

22. M. A. Barique, H. Ohigashi, Polymer 2001, 42, 4981-4987.

23. V. Kochervinskii, Cryst. Rep. 2003, 48, 649-675.

24. S. S. Guo, W. P. Li, C. L. Sun, X. Z. Zhao, Z. Peng, H. L. W. Chan, C. L. Choy, S. T. Lau, Mater. Chem. Phys. 2004, 83, 298-306.

25. J. Jin, S.-G. Lu, C. Chanthad, Q. Zhang, M. A. Haque, Q. Wang, Adv. Mater. 2011, 23, 3853-3858.

26. R. Tanaka, K. Tashiro, M. Kobayashi, Polymer 1999, 40, 3855-3865.

27. N. Alves, A. M. G. Plepis, J. A. Giacometti, O. N. Oliveira, Ferroelectrics Letters Section 1998, 23, 99-105.

28. F. Xia, Y. K. Wang, H. Li, C. Huang, Y. Ma, Q. M. Zhang, Z. Y. Cheng, F. B. Bateman, J. Polym. Sci. B: Polym. Phys. 2003, 41, 797-806.

29. J. S. Lee, A. A. Prabu, K. J. Kim, Polymer 2010, 51, 6319-6333.

30. K. Omote, H. Ohigashi, K. Koga, J. Appl. Phys. 1997, 81, 2760-2769.

31. A. Polyakova, E. V. Stepanov, D. Sekelik, D. A. Schiraldi, A. Hiltner, E. Baer, J. Polym. Sci. B: Polym. Phys. 2001, 39, 1911-1919.

32. M. J. Elhibri, D. R. Paul, J. Appl. Polym. Sci. 1986, 31, 2533-2560.

33. D. N. Busick, R. J. Spontak, C. M. Balik, Polymer 1999, 40, 6023-6029.

34. S. Hietala, E. Skou, F. Sundholm, Polymer 1999, 40, 5567-5573.

35. T. Lehtinen, G. Sundholm, F. Sundholm, J. Appl. Electrochem. 1999, 29, 677-683.

36. L. Monson, S. I. Moon, C. W. Extrand, J. Appl. Polym. Sci. 2009, 111, 141-147.

37. R. Gregorio, M. M. Botta, J. Polym. Sci. B: Polym. Phys. 1998, 36, 403-414. 
38. H. L. W. Chan, Z. Zhao, K. W. Kwok, C. L. Choy, Proceedings of the 8th International Symposium on Electrets (ISE-8), Paris, France, Sept. 7-9, 1994.

39. W. Li, L. Jiang, Y. Zhu, J. Wang, J. Appl. Polym. Sci. 2006, 102, 4258-4263.

40. X. F. Cui, M. Zhao, Q. Jiang, Thin Solid Films 2005, 472, 328-333.

41. A. A. Prabu, K. J. Kim, C. Park, Vibr. Spectr. 2009, 49, 101-109.

42. J. B. Ngoma, J. Y. Cavaille, J. Paletto, J. Perez, Polymer 1991, 32, 1044-1048.

43. F. J. Baltá Calleja, C. Santa Cruz, A. González Arche, E. López Cabarcos, J. Mater. Sci. 1992, 27, 2124-2130.

44. T. Yagi, M. Tatemoto, J.-I. Sako, Polym. J. 1980, 12, 209-223.

45. G. Teyssedre, A. Bernes, C. Lacabanne, Thermochim. Acta 1993, 226, 65-75.

46. S. Dalle Vacche, F. Oliveira, Y. Leterrier, V. Michaud, D. Damjanovic, J.-A. E. Månson, J. Mater. Sci. 2012, 47, 4763-4774.

47. D. T. Grubb, in Materials Science and Technology. Volume 12. Structure and Properties of Polymers, Eds. R. W. Cahn, P. Haasen, E. J. Kramer, VCH, New-York, 1993; Chapter 7, pp 301-356.

48. R. Ruggerone, V. Geiser, S. Dalle Vacche, Y. Leterrier, J.-A. E. Månson, Macromolecules 2010, 43, 10490-10497.

49. R. E. Wetton, Polym. Test. 1984, 4, 117-129.

50. T. R. Dargaville, M. Celina, P. M. Chaplya, J. Polym. Sci. B: Polym. Phys. 2005, 43, 1310-1320.

51. R. Gregorio, E. M. Ueno, J. Mater. Sci. 1999, 34, 4489-4500.

52. Y. Yun, Y. Jiang, Z. Wu, Z. Hongjuan, Y. Yajie, L. Wei, Proceedings of the 12 th International Symposium on Electrets (ISE-12), Salvador, Brazil, Sept. 11-14, 2005.

53. Y. Leterrier, Prog. Mater. Sci. 2003, 48, 1-55.

54. D. W. Van Krevelen, Properties of Polymers. 3rd Ed., Elsevier, New-York, 1990.

55. B. Singh, J. Bouchet, Y. Leterrier, J.-A. E. Månson, G. Rochat, P. Fayet, Surf. Coat. Technol. 2007, 202, 208-216.

56. G. Teyssedre, A. Bernes, C. Lacabanne, J. Polym. Sci. B: Polym. Phys. 1993, 31, $2027-$ 2034.

57. V. Bharti, H. Xu, Z. Y. Cheng, T. Mai, Q. M. Zhang, IEEE Trans. Dielect. Elect. Insul. 2001, 8, 718-724.

58. M. Mackey, L. Flandin, A. Hiltner, E. Baer, J. Polym. Sci. B: Polym. Phys. 2011, 49, 1750-1761.

59. J. H. Petropoulos, J. Polym. Sci. B: Polym. Phys. 1985, 23, 1309-1324.

60. M. Drieskens, R. Peeters, J. Mullens, D. Franco, P. J. Lemstra, D. G. HristovaBogaerds, J. Polym. Sci. B: Polym. Phys. 2009, 47, 2247-2258.

61. A. S. Michaels, H. J. Bixler, J. Polym. Sci. 1961, 50, 393-412.

62. L. E. Nielsen, J. Macromol. Sci. A: Chem. 1967, 1, 929-942.

63. E. L. Cussler, S. E. Hughes, W. J. Ward, R. Aris, J. Membr. Sci. 1988, 38, 161-174.

64. G. H. Fredrickson, J. Bicerano, J. Chem. Phys. 1999, 110, 2181-2188.

65. A. A. Gusev, H. R. Lusti, Adv. Mater. 2001, 13, 1641-1643.

66. S. Takahashi, H. A. Goldberg, C. A. Feeney, D. P. Karim, M. Farrell, K. O'Leary, D. R. Paul, Polymer 2006, 47, 3083-3093.

67. B. Neway, M. S. Hedenqvist, V. B. F. Mathot, U. W. Gedde, Polymer 2001, 42, 53075319.

68. M. Niwa, K. Yamazaki, Y. Murakami, Ind. Eng. Chem. Res. 1991, 30, 38-42.

69. A. Tewari, A. M. Gokhale, Mater. Sci. Eng. A: Struct. Mater. Prop. Microstr. Proc. 2004, 385, 332-341. 